\title{
Alimentación e identidad nacional
}

\author{
Pablo Yankelevich
}

JosÉ LUIS JUÁREZ LÓPEZ, 2008

\section{Nacionalismo culinario. La cocina mexicana en el siglo $X X$}

Conaculta, México, 359 pp.

$\mathrm{E}^{\mathrm{n}}$ la comida confluye la doble condición humana de seres biológicos y culturales. Nuestra naturaleza nos obliga a comer, no podemos dejar de alimentarnos. Sobre lo que acontece con nuestros organismos frente a una mala o buena alimentación se ocupan las ciencias médicas, pero hay otros asuntos no menos importantes que giran en torno al significado que las comunidades humanas otorgan a la cocina y a la comida, a determinados alimentos, a su preparación y, por supuesto, al acto mismo de comer. Estos asuntos han sido un campo privilegiado por la antropología casi desde su origen como disciplina. Lévi-Strauss, hace ya muchos años, sentenció que la mecánica de transformar la comida cruda en cocida marca el inicio de la humanidad. La cocina, el cocer los alimentos, emerge entonces como el es-

\section{Feeding and National Identity}

PABlo YanKeleVICH: Instituto Nacional de Antropología e Historia, México pabloy@unam.mx

Desacatos, núm. 34, septiembre-diciembre 2010, pp. 182-184

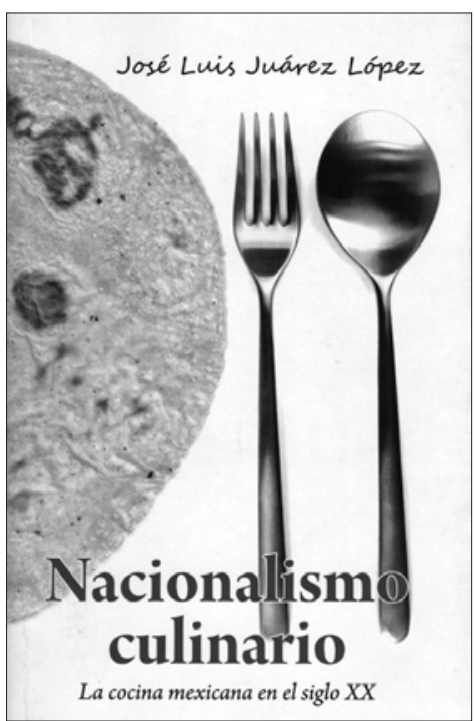

pacio donde el hombre articula la naturaleza y la cultura.

Hace ya varias décadas asistimos a la constitución de un campo disciplinario: la llamada antropología alimentaria, interesada en estudiar las sociedades humanas desde el mirador de sus estrategias y elecciones culinarias: qué se puede y qué no se 
puede comer, el tabú alimenticio fijando la frontera entre lo prohibido y lo permitido. El tabú como instrumento que recorta los límites de una identidad tribal, comunal, religiosa o sexual. En este sentido, los estudios antropológicos desde diversas aproximaciones y perspectivas teóricas han dedicado su atención a explorar la cocina y la comida, entendiéndolas como alimento del cuerpo, pero también del alma.

México no ha sido una excepción. Son numerosos los estudios que relacionan a la comida con la religiosidad, los rituales y las tradiciones de más de medio centenar de grupos étnicos que habitan el territorio nacional. Se trata de un fenómeno cultural observado y analizado como parte del ciclo de la vida y, por supuesto, del agrícola: el nacimiento y la muerte, la siembra y la cosecha. Abundan los estudios sobre la llamada comida mexicana en las cocinas y en las mesas, en las fiestas, en los templos, en las cunas y en los cementerios. Todos arrojan luz sobre los significados de usos y prácticas culinarias en la conformación identitaria de etnias y comunidades.

Pero qué sucede con identidades mayores, qué sucede con la conformación de la más importante de las identidades desde el triunfo de la modernidad política: la identidad nacional. ¿La culinaria puede ser parte de la dimensión étnica, tan necesaria de ser incorporada en los estudios sobre la génesis del sentimiento nacional? Es decir, los sabores, los olores, los colores y las texturas de los alimentos, así como las técnicas

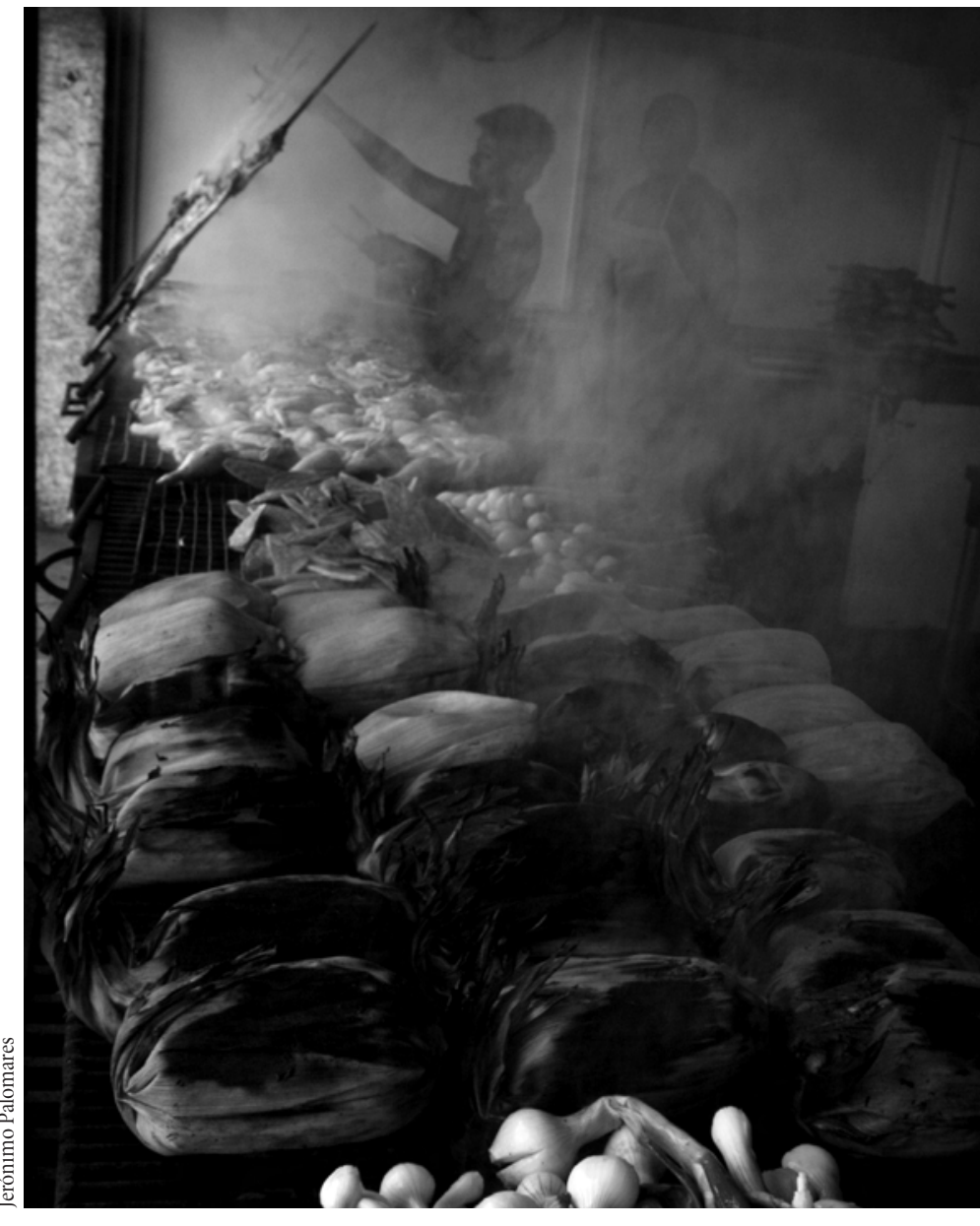

Sin título

para su elaboración y los rituales de su degustación, deberían ser indagados como parte fundamental en la invención de mitos, símbolos y valores que vinculan a sucesivas generaciones de mexicanos, permitiendo establecer los límites de un nosotros desde el cual se amalgaman líneas de diferenciación cultural que permiten regular la relación entre los mexicanos y aquellos que no lo son.

Esta preocupación orienta la investigación de Juárez López, quien cree posible indagar el mundo de la culinaria como parte de ese acervo de recuerdos y mitos que dotan de sentido la identidad nacional. Se trata de una investigación que desde la antropología y la historia analiza y explica los mecanismos que hicieron posible convertir la cocina mexicana en uno de los afluentes de la nacionalidad.

Para la realización de esta empresa, el autor echó mano de una fuente documental escasamente explorada: 
los recetarios de cocina diseminados en folletos, en prensa periódica, en revistas, y hasta aquellos obsequiados con utensilios de cocina o alimentos industrializados. También hizo una acuciosa revisión bibliográfica de obras dedicadas a la cocina mexicana. Más que una historia de la culinaria mexicana, el libro está atravesado por el interés en reconstruir el discurso sobre esa culinaria. En buena medida, el lector puede advertir un ancho horizonte de rescate de materiales de la más diversa naturaleza, desde los clásicos como Alfonso Reyes y Salvador Novo, hasta figuras poco conocidas o anónimas que dejaron su impronta en notas de periódicos, folletos de ocasión o en las etiquetas de las sopas Campbell.

La amplia circulación de estos

184 materiales, muchos de ellos producto de iniciativas empresariales privadas, pero no pocos a cargo del sector público a través de la Secretaría de Educación Pública, del Instituto Mexicano del Seguro Social y de la Secretaría de Salud, entre otras instituciones oficiales, que se dieron a la tarea de imprimir masivamente recetarios e historias de la cocina regional y étnica, da cuenta de un emprendimiento de creación y difusión de obras que contribuyeron a instalar la noción de una cocina auténticamente nacional.

Hacia principios del siglo XX, Francia era el punto de referencia y validación por excelencia para casi todos los comportamientos y saberes de las élites mexicanas. Si esto fue así para la política, la banca o la ciencia, mucho más para la cocina.
Contra ese modelo culinario debieron enfrentarse los platillos típicos y las comidas autóctonas. En buena medida, el libro narra las batallas de una guerra sostenida a lo largo de más de medio siglo, cuyo objetivo fue ensalzar la comida nacional, no para desplazar a la extranjera, sobre todo la francesa, sino para que los chefs franceses la reconocieran como digna de una nación civilizada.

En las páginas de Nacionalismo culinario. La cocina mexicana en el siglo XX se explora un mundo heterogéneo de regiones, cocinas, tradiciones, recetas y comidas, animado por un doble interés: por una parte, encontrar los momentos en los que desde esa multiplicidad de sabores emergieron algunos como arquetipos de la mesa mexicana - el mole patriótico, por ejemplo—; por otra, el texto descubre y explica la consagración de lo múltiple, de la diversidad de cocinas como parte del discurso culinario nacional. En este sentido, exhibe matices sobre la escasa densidad histórica del rescate de lo indígena en las representaciones de la culinaria mexicana. En otro orden de preocupaciones, también se estudia el impacto de la industria del turismo en la consagración de la idea de lo diverso de la gastronomía nacional.

El autor repara tanto en las recetas y sus ingredientes como en la elaboración, presentación y degustación de los platillos mexicanos. El mundo de las técnicas y las costumbres es contemplado en cada uno de los ocho capítulos en los que está organizado el libro, dando cuenta de tradiciones inventadas con tal efecti- vidad que se han situado de manera definitiva en los discursos culinarios a lo largo del siglo xx. Por último, la obra se interna en un territorio de actualidad: ya nadie duda de la existencia de una comida auténticamente nacional: las enchiladas y las quesadillas han dejado de tener un valor peyorativo. Por el contrario, México participa en el boom gastronómico que se registra a escala global y la cocina mexicana ocupa en éste un sitial de primer orden. Sobre estos temas también trabajó Juárez López, no sin antes revisar esa explosión de libros de fotografía culinaria en la que México y sus platillos comparten los escaparates en las librerías del mundo con obras dedicadas a la pintura de Gustav Klimt o a la arquitectura contemporánea.

En síntesis, se trata de una investigación que sigue las huellas del proceso que condujo a la consagración de la comida de México al punto de convertirla en uno de los afluentes de identidad nacional. Orgullo que no siempre existió y que en las últimas fechas parece acrecentarse por el éxito internacional que han tenido guisados, chiles y tequilas en los principales centros del quehacer gastronómico mundial. Nacionalismo culinario, entonces, confirma aquello que nos ha señalado hace tiempo la antropología: el mundo de la comida es un territorio plagado de sentidos y de símbolos mediante los cuales las comunidades crean y reproducen sus identidades. 